\title{
TITLE: DIASTOLIC DYSFUNCTION AND NEW ONSET OF AF AFTER CABG
}

AUTHORS: Massimiliano Meineri MD, George Djaiani MD, Ludwik Fedorko MD, Marcin Wasowicz MD, Humara Poonawala MD, Jo Carroll RN, Jacek Karski MD

AFFILIATION: Department of Anesthesia \& Pain Management, Toronto General Hospital, UHN, University of Toronto, 200 Elizabeth Street, Toronto, ON, M5G 2C4

INTRODUCTION: Atrial fibrillation (AF) affects 20-30\% of the patients undergoing coronary artery bypass graft $(\mathrm{CABG})$ surgery ${ }^{1}$. AF is associated with significant morbidity and mortality ${ }^{2-4}$. Its predictors are: advanced age, male sex, history of AF and congestive heart failure ${ }^{5}$. Left ventricular (LV) diastolic dysfunction (DD) is a frequent occurrence during and after CABG Surgery ${ }^{6}$ and may cause elevated pulmonary pressure and increased left atrial size leading to increased risk of new onset of AF.

METHODS: Following REB approval, 20 consented patients undergoing elective CABG surgery were enrolled in the study. Anesthesia and cardiopulmonary bypass (CPB) were standardized as per institutional protocol. A complete transesophageal echocardiographical examination was performed before CPB and repeated after chest closure. LV diastolic function (DF) was evaluated according to the following parameters as per guidelines ${ }^{7}$ : Mitral inflow flow profile (Peak E and A velocities, Deceleration Time, E/A ratio, Propagation velocity Vp), Pulmonary veins flow profile (Peak S and D velocities, S/D ratio, A duration), Mitral annular A' and E' velocities measured with tissue Doppler imaging (TDI). The primary outcome was to determine if diastolic dysfunction is associated with an increased risk of postoperative AF.

RESULTS: The diastolic function measures are displayed in the following table.

\begin{tabular}{|c|c|c|c|c|}
\hline & \multicolumn{2}{|l|}{ Induction } & \multicolumn{2}{|l|}{ Chest closure } \\
\hline & $\begin{array}{ll}\text { Normal } & \text { Diastolic } \\
(\mathrm{n}=14)\end{array}$ & $\begin{array}{l}\text { Function } \mid \begin{array}{l}\text { Diastolic Dysfunction } \\
(\mathrm{n}=6)\end{array} \\
\end{array}$ & $\begin{array}{l}\text { Normal Diastolic } \\
(\mathrm{n}=12)\end{array}$ & $\begin{array}{ll}\text { Function } & \begin{array}{l}\text { Diastolic Dysfunction } \\
(\mathrm{n}=8)\end{array} \\
\end{array}$ \\
\hline E/A ratio & $1.3 \pm 0.4$ & $1.0 \pm 0.4$ & $1.4 \pm 0.3$ & $1.2 \pm 0.3$ \\
\hline $\mathrm{S} / \mathrm{D}$ ratio & $1.7 \pm 0.3$ & $1.1 \pm 0.3$ & $1.6 \pm 0.4$ & $1.0 \pm 0.2$ \\
\hline DT (msec) & $189 \pm 18$ & $245 \pm 67$ & $191 \pm 26$ & $267 \pm 70$ \\
\hline$E^{\prime} / A^{\prime}$ ratio & $1.2 \pm 0.3$ & $0.6 \pm 0.23$ & $1.3 \pm 0.2$ & $0.66 \pm 0.24$ \\
\hline $\mathrm{Vp}(\mathrm{cm} / \mathrm{s})$ & $63 \pm 10$ & $31 \pm 14$ & $66 \pm 11$ & $29 \pm 10$ \\
\hline
\end{tabular}

Age, gender, coexisting diseases, number of grafts, duration of CPB and hemodynamic variables were similar among the patients population. Seven patients had a new onset of $\mathrm{AF}, 4$ of them developed DD after $\mathrm{CPB}$, and 3 had DD prior to surgery with no improvement after revascularization.

DISCUSSION: The improvement of DD after CPB (2 pt) can be likely related to resolving ischemic process after revascularization. The developed DD after CPB (8 pt) is likely subsequent to the ischemia-reperfusion injury. Our preliminary data suggest that the presence of DD after CABG surgery may correlate with an increased risk of new onset of AF.

REFERENCES: ${ }^{1}$ Circulation 81: III48-53; ${ }^{2} \mathrm{~J}$ Am Coll Cardiol 37:371-8 ; ${ }^{3} \mathrm{~J}$ Am Coll Cardiol 32:695-703 ; ${ }^{4}$ Anesthesiology 91:936-44 ; ${ }^{5}$ Jama 276:300-6 ; ${ }^{6}$ Ann Thorac Surg 56:539-49; ${ }^{7}$ Journal of the American Society of Echocardiography 9:736-60. 
3. Prunier F, Gaertner R, Louedec L, Baptiste Michel, Doppler echocardiographic estimation of left ventricular end diastolic pressure after MI in rats, Am J physiol, Jul 2001, 283:346-352.

4. Tei C, Ling LH, Hodge DO, Bailey KR, Oh JK, Rodenheffer RJ, new index of combined systolic and diastolic myocardial performance, a simple and reproducible measure of cardiac function, a study in normal and dilated cardiomyopathy, J Cardiol, 1995; 26:357-366. 